\title{
Immunosuppressive treatment in severe connective tissue diseases: effects of low dose intravenous cyclophosphamide
}

Ignacio Martin-Suarez, David D'Cruz, Mohammed Mansoor, Ana Paula Fernandes, Munther A Khamashta, Graham R V Hughes

\begin{abstract}
Objective-To review our experience with low dose intravenous pulse cyclophosphamide in the treatment of patients with severe connective tissue diseases.

Patients-Ninety patients (68F:22M) with severe connective tissue diseases received a total of 883 cyclophosphamide pulses with 78 of 90 patients initially having weekly $500 \mathrm{mg}$ pulses for a median of three (2-10) weeks. Diagnoses included: systemic lupus erythematosus (SLE) $(n=43)$; systemic vasculitides $(n=42)$; idiopathic inflammatory myopathies $(n=4)$; mixed essential cryoglobulinaemic vasculitis $(n=1)$. The median age was 48 (range 22-76) years with a median disease duration of 94 (18-250) months.
\end{abstract}

Results-Complete or partial remission was noted in 68 of 90 patients $(75.5 \%)$ after a median follow up of 56 (5-213) months. At follow up significant median changes were noted in SLE patients: erythrocyte sedimentation rate (ESR) from 44 to 22 mm 1st hour; anti-dsDNA antibody concentrations from 81 to $48 \mathrm{IU} / \mathrm{ml}$; proteinuria from 2.5 to $1.5 \mathrm{~g} /$ day; serum albumin from 36 to $40 \mathrm{~g} / 1$; complement C3 from 0.88 to $0.90 \mathrm{~g} / 1$, and $\mathrm{C} 4$ from 0.18 to $0.22 \mathrm{~g} / 1$. In the vasculitis patients significant median changes were seen in: ESR from 44 to $15 \mathrm{~mm}$ 1st hour; $C$ reactive protein (CRP) from 16 to $5 \mathrm{~g} / \mathrm{dl}$; neutrophils from 8.55 to $4.3 \times 10^{9} / 1$; platelets from 340 to $261 \times 10^{3} / 1$, and haemoglobin from 12.6 to $13.2 \mathrm{~g} / \mathrm{dl}$. Patients with Churg-Strauss syndrome, Wegener's granulomatosis, and neuropsychiatric lupus showed the best initial response but $58 \%$ of Wegener's patients relapsed. Median corticosteroid doses were significantly reduced from 15 (5-60) mg to 10 (3-35) $\mathrm{mg}$ daily. Adverse events: infections ( 7 patients), neutropenia (5), lymphopenia (18), and haemorrhagic cystitis (1 intravenous and 2 oral cyclophosphamide), allergies to mesna (2). None of the women at risk had prolonged amenorrhoea. Five patients doubled their serum creatinine and five died from sepsis (2) or severe disease (3).

Conclusion-Treatment of severe connective tissue diseases with 'low dose' intravenous cyclophosphamide pulses compares in efficacy with the higher monthly doses previously advocated. Treatment was well tolerated with fewer adverse effects and most significantly, there were no cases of premature ovarian failure.

(Ann Rheum Dis 1997;56:481-487)

Intravenous pulse cyclophosphamide treatment is widely used in the management of autoimmune connective tissue diseases and has resulted in a dramatic improvement in patient outcome. Perhaps the most important application has been in the therapeutic approach to the vasculitides, especially the clinical experience with cyclophosphamide in treating Wegener's granulomatosis.

Untreated Wegener's granulomatosis usually has a rapidly fatal course with a mean survival of five months and a one year mortality of $82 \% .{ }^{12}$ Although corticosteroids may improve the mean survival to 12.5 months, it is clear that the long term prognosis is not significantly changed by corticosteroids alone. ${ }^{3}$ The introduction of cyclophosphamide has radically improved survival ${ }^{4}$ and has also proved to be beneficial in other vasculitic syndromes ${ }^{5}$ as well as in active polymyositis.

Cyclophosphamide is well established in the treatment of lupus nephritis where it reduces the risk of end stage renal failure ${ }^{7-10}$ Currently, intravenous doses of cyclophosphamide calculated on a surface area basis have tended to be high (of the order of 750-1250 mg) and the infection rate has consequently been high - in some series up to $25 \%{ }^{811}$

Over the past 10 years, in an attempt to reduce the incidence of infections and other adverse effects, we have treated patients with severe connective diseases using a less aggressive intravenous cyclophosphamide regimen that does not aim to induce leucopenia as a treatment goal in the induction phase of treatment. Our reasons were twofold. Firstly, we felt that the lower dose regimen, being better tolerated was more suitable for outpatient practice. Secondly, we felt that there was an urgent need to attempt to reduce the three most serious complications of cyclophosphamide: premature ovarian failure, infection (especially Herpes zoster), and haemorrhagic cystitis in our patients.

We have described our preliminary experience with this regimen. ${ }^{12} 13$ We present here a retrospective analysis of 90 patients with severe connective tissue diseases treated with a 
total of 883 pulses using this low dose intravenous cyclophosphamide regimen.

\section{Methods}

PATIENTS

Ninety patients diagnosed as having severe progressive connective tissue diseases were given low dose intravenous cyclophosphamide treatment between January 1990 and November 1994 and all were followed up until April 1995. These patients were new referrals or patients who had previously either relapsed or developed new organ involvement despite treatment with oral prednisolone $(n=38)$, azathioprine $(n=31)$ or methylprednisolone pulses $(n=31)$, or all three. These patients were followed up in the Lupus and Vasculitis clinics at St Thomas's Hospital for a median of 56 (range 5-213) months after the first pulse of cyclophosphamide. There were 43 patients with systemic lupus erythematosus (SLE), 42 with systemic vasculitides, four with idiopathic inflammatory myopathies, and one patient with mixed essential cryoglobulinaemic vasculitis. Patients with SLE, Wegener's granulomatosis, Churg-Strauss syndrome, and polyarteritis nodosa were classified according to the respective American College of Rheumatology classification criteria. ${ }^{14}{ }^{15}$ There were 68 women and 22 men, with a median age of 48 (22-76) and a median disease duration of 94 (18-250) months. Forty women aged under 40 all had regular menses. There were 71 white, 12 Asian, and seven Afro-Caribbean patients.

CLINICAL ASSESSMENT

Complete clinical examination and laboratory tests were carried out before treatment with intravenous cyclophosphamide, after the first three to four pulses to assess the initial response to therapy, at the end of the treatment course, and at the end of the follow up period. All patients were assessed for disease duration, clinical evidence of organ involvement, erthrocyte sedimentation rate (ESR), C reactive protein (CRP), neutrophil, lymphocyte and platelet counts, haemoglobin value, urine analysis, 24 hour urine protein excretion and creatinine clearance, blood urea, serum creatinine, and albumin. Complement values (C3 and $\mathrm{C} 4$ ) were assayed by radial immunodiffusion (Behring). Anti-ds DNA antibodies were measured by solid phase enzyme linked immunosorbent assay. ${ }^{16}$ In terms of assessing ovarian function, we arbitrarily defined premature ovarian failure as prolonged amenorrhoea for at least 12 months in a woman with previously regular menses under the age of 40 .

CRITERIA FOR REMISSION

Complete clinical remission was arbitrarily defined as the complete absence of clinical and laboratory evidence of disease activity for at least three months. Partial remission was defined as clear evidence of improvement in disease activity with at least $50 \%$ improvement in laboratory parameters for at least three months. Patients who did not meet these criteria were regarded as treatment failures. Poor renal outcome was defined as a doubling of serum creatinine or the development of end stage renal failure requiring dialysis.

INDICATIONS FOR INTRAVENOUS

CYCLOPHOSPHAMIDE TREATMENT

Patients who received intravenous cyclophosphamide treatment were either new patients receiving no therapy who had active disseminated systemic vasculitis complicated by renal, pulmonary, cardiac or neurological involvement; SLE complicated by glomerulonephritis, widespread cutaneous vasculitis, severe cardiac or pulmonary disease, central or peripheral neurological involvement or patients with these diseases who developed these complications despite treatment with low dose prednisolone or azathioprine, or both. Intravenous cyclophosphamide was contraindicated in any patient who was pregnant or with evidence of sepsis. Those with significant renal impairment (creatinine clearance less than 30 $\mathrm{ml} / \mathrm{min}$ ) received $250 \mathrm{mg}$ pulses of cyclophosphamide. Patients receiving azathioprine had the drug stopped for at least a week before starting intravenous cyclophosphamide to avoid excessive immunosuppression and bone marrow toxicity.

INTRAVENOUS CYCLOPHOSPHAMIDE

Intravenous cyclophosphamide $(500 \mathrm{mg}$ ) was given in 100-500 ml saline over one hour accompanied by adequate oral hydration to promote frequent voiding of dilute urine in the first 24 hours after drug administration. To reduce bladder toxicity further, mesna (Uromitexan, Boehringer) was given in 816 of the 883 pulses. ${ }^{17}$ Mesna was initially given (100 $\mathrm{mg}$ ) intravenously at the start of the cyclophosphamide infusion followed by $200 \mathrm{mg}$ orally at four and eight hours. Antiemetics (metoclopramide or where necessary ondansetron) were used in all patients. Treatment was given weekly providing there was no evidence of severe neutropenia at the time of the next intravenous pulse.

Once a clear response (either complete or partial remission) was seen and in particular once major organ involvement was seen to be improving after weekly intravenous cyclophosphamide treatment, maintenance therapy was started with either azathioprine $(2 \mathrm{mg} / \mathrm{kg} / \mathrm{day})$ or continued monthly intravenous cyclophosphamide (500 mg pulses). The choice depended on the clinical response to the initial pulse cyclophosphamide treatment: azathioprine was used in patients achieving complete remission and monthly intravenous cyclophosphamide was continued in patients who had either not responded or had achieved partial remission with continuing disease activity.

STATISTICAL ANALYSIS

Descriptive statistics for the patients were obtained and are reported as medians with ranges or frequencies as appropriate. Non-parametric tests, Wilcoxon's rank sum test, and the $\chi^{2}$ test were used in analysis. Statistical significance was indicated by a $p$ value $<0.05$. 
Table 1 Total and median numbers of pulses and cumulative doses of intravenous cyclophosphamide received by patients in each diagnostic group

\begin{tabular}{lccccc}
\hline & Patients $(n)$ & $\begin{array}{l}\text { Total number of } \\
\text { pulses }\end{array}$ & $\begin{array}{l}\text { Median per } \\
\text { patient }\end{array}$ & $\begin{array}{l}\text { Range } \\
\text { (range) }\end{array}$ \\
\hline All patients & 90 & 883 & 8 & $2-50$ & 3 \\
SLE & 43 & 353 & 6 & $2-26$ & $2.5(1-25)$ \\
All systemic vasculitis & 42 & 507 & 9 & $2-50$ & $4.5(1-25)$ \\
Wegener's granulomatosis & 19 & 271 & 11 & $4-50$ & $5.5(2-25)$ \\
Polyarteritis nodosa & 8 & 63 & 8.5 & $2-14$ & 4 \\
Churg-Strauss syndrome & 3 & 29 & 10 & $9-10$ & $5.5(5-7)$ \\
Undifferentiated systemic vasculitis & 12 & 136 & 7.5 & $3-11$ & $2.25(1.5-5.5)$ \\
Idiopathic inflammatory myopathies & 4 & 23 & 4.5 & $3-11$ & $2.25(1.5-5.5)$ \\
Mixed essential cryglobulinaemia & 1 & 8 & NA & NA & 4 \\
\hline
\end{tabular}

\section{Results}

Seventy four patients initially received weekly intravenous cyclophosphamide therapy: 44 received weekly pulses for a median of three consecutive weeks (range 2-10) followed by monthly pulses for a median of four (1-42) months and 30 patients received only weekly intravenous cyclophosphamide pulses for a median of three (2-9) weeks followed by maintenance treatment. Sixteen patients were given intravenous cyclophosphamide every month for a median of eight (3-37) months.

Most patients (78 of $90,87 \%$ ) received 500 $\mathrm{mg}$ pulses, though four patients with severe systemic vasculitis who were obese received $750 \mathrm{mg}$ pulses and eight patients who had renal impairment (creatinine clearance less than $30 \mathrm{ml} / \mathrm{min}$ ) received $250 \mathrm{mg}$ pulses. The patients were subsequently treated with prednisolone alone $(n=48)$, prednisolone and azathioprine $(\mathrm{n}=26)$, oral cyclophosphamide $(n=11)$, etoposide $(n=3)$ or methotrexate $(n=2)$. Twenty two patients received a second course of monthly pulses of cyclophosphamide indicated by the clinical severity of the disease or disease relapse. Table 1 shows the median number of pulses and cumulative dose of intravenous cyclophosphamide given according to diagnosis.

RESPONSE TO TREATMENT

Complete or partial disease remission was noted in 68 of 90 patients $(75.5 \%)$ at the end of the median follow up period of $56(5-213)$ months (table 2). The most striking improvements were noted in patients with Churg-Strauss and Wegener's granulomatosis especially in patients with upper airway and ocular involvement, usually within two to six weeks of the start of intravenous cyclophosphamide. The median (range) period to complete remission in those who responded to treatment was: SLE: 21.5 (1-2) weeks, undifferentiated systemic vasculitis: 15 (4-47) weeks, Wegener's granulomatosis: 22 (9-175) weeks, and ChurgStrauss syndrome: 22 (21-31) weeks.

Overall, the median prednisolone dose was significantly reduced from 15 (5-60) mg daily at the start of intravenous cyclophosphamide treatment to $10(3-35) \mathrm{mg}$ daily $(\mathrm{p}<0.05)$ at the end of follow up.

There were 22 of 90 patients (24.5\%) who failed to respond to treatment. These included six lupus nephritis patients, two lupus patients with severe interstitial lung disease and two with cerebral lupus, one patient with dermatomyositis, four patients with Wegener's granulo- matosis, four with undifferentiated systemic vasculitis, and three patients with polyarteritis nodosa. Of these patients, histology review showed predominantly chronic or fibrotic changes in renal or muscle samples in six patients. There were five deaths and six patients were lost to follow up, one with systemic vasculitis and five with SLE.

SYSTEMIC LUPUS ERYTHEMATOSUS

Forty three patients with SLE were treated with intravenous cyclophosphamide with a median of six (2-26) pulses per patient with a median cumulative dose of $2.5(1-13) \mathrm{g}$. In the SLE group as a whole, there were significant improvements after a median of three (2-7) pulses in ESR, 24 hour protein excretion, serum albumin, anti-dsDNA antibody and C4 values supporting our clinical finding of a rapid response to weekly intravenous cyclophosphamide (table 3). Maintenance treatment started after the initial weekly infusions resulted in continued significant improvements from baseline in ESR, 24 hour protein excretion, serum albumin, anti-dsDNA antibody and C3 and $\mathrm{C} 4$ values.

Twenty six patients had lupus nephritis with persistent proteinuria ( $>1 \mathrm{~g} /$ day) or abnormal urine sediments, or both, confirmed by renal biopsy in 22 patients. Ten biopsy samples had focal proliferative nephritis (WHO grade III) and 12 showed diffuse proliferative nephritis (WHO grade IV). Twenty of these 26 patients with lupus nephritis responded well to intravenous cyclophosphamide treatment. Table 3 shows that there were significant improvements in median 24 hour proteinuria, anti-dsDNA antibody values, serum albumin and $\mathrm{C} 3$ and $\mathrm{C} 4$ values. The median serum cre-

Table 2 Clinical response to induction and maintenance treatment at the end of follow up

\begin{tabular}{lcc}
\hline Diagnosis & $\begin{array}{c}\text { Patients } \\
(n)\end{array}$ & $\begin{array}{l}\text { Clinical response } \\
\text { (complete or partial } \\
\text { remission) (\%) }\end{array}$ \\
\hline SLE & 43 & $33(77)$ \\
Nephritis & 26 & $20(77)$ \\
Neuropsychiatric & 10 & $8(80)$ \\
Myocarditis & 2 & $2(100)$ \\
Interstitial pneumonitis & 2 & $0(0)$ \\
Severe systemic flare & 3 & $3(100)$ \\
Systemic vasculitis & 42 & $31(74)$ \\
Wegener's granulomatosis & 19 & $15(79)$ \\
Undifferentiated vasculitis & 12 & $8(67)$ \\
Polyarteritis nodosa & 8 & $5(63)$ \\
Churg-Strauss syndrome & 3 & $3(100)$ \\
Idiopathic inflammatory & & $3(75)$ \\
$\quad$ myopathy & 4 & $1(100)$ \\
$\quad$ Mixed essential & &
\end{tabular}


Table 3 Laboratory changes before and after intravenous cyclophosphamide treatment in SLE. Values are median (range)

\begin{tabular}{|c|c|c|c|c|c|c|c|}
\hline \multirow{2}{*}{$\begin{array}{l}\text { Laboratory tests } \\
\text { ESR (mm 1st h) }\end{array}$} & \multicolumn{2}{|c|}{ Before treatment } & $\begin{array}{l}\text { Initial response } 3 \text { (2-7) } \\
\text { weeks } 3(2-7) \text { pulses }\end{array}$ & \multicolumn{2}{|c|}{$\begin{array}{l}\text { After the course of treatment } 5.3 \\
(0.25-13) \text { months } 5(2-26) \text { pulses }\end{array}$} & \multicolumn{2}{|c|}{$\begin{array}{l}\text { At follow up } 56 \\
\text { (5-213) months }\end{array}$} \\
\hline & 44 & $(10-140)$ & $27.5(2-150)^{\star}$ & 26 & $(2-107)^{\star}$ & 22 & $(1-130)^{\star}$ \\
\hline $\mathrm{Hb}(\mathrm{g} / \mathrm{dl})$ & 12.2 & $(5.8-15.7)$ & $(8-16)$ & 12.7 & $(7.6-15.8)$ & 12.5 & $(6.2-15.2)$ \\
\hline Neutrophils $\left(\times 10^{9} / 1\right)$ & 5.5 & $(0.9-31)$ & $(1.2-2.6)$ & 4.6 & $(1.2-2.8)$ & 4.3 & $(1.2-13.5)$ \\
\hline Lymphocytes $\left(\times 10^{9} / 1\right)$ & 1.2 & $(0.12-8)$ & $(0.2-5)$ & 1 & $(0.1-4.6)$ & 1 & $(0.08-4.6)$ \\
\hline Platelets $\left(\times 10^{3} / 1\right)$ & 304 & $(11-1280)$ & $(104-610)$ & 277 & $(8-698)$ & 261 & $(69-468)$ \\
\hline $\mathrm{CRP}(\mathrm{g} / \mathrm{dl})$ & 12 & $(5-230)$ & $(5-103)$ & 10 & $(5-121)$ & 5 & $(5-180)$ \\
\hline Creatinine $(\mu \mathrm{mol} / \mathrm{l})$ & 93 & $(45-250)$ & $(49-255)$ & 94 & $(12-278)$ & 112 & $(51-287)$ \\
\hline $24 \mathrm{~h}$ proteinuria $(\mathrm{g} / \mathrm{d})$ & 2.5 & $(0.3-13)$ & $(0.2-6)^{\star}$ & 1.8 & $(0.2-9.3)^{\star}$ & 1.5 & $(0.1-7)^{\star}$ \\
\hline Albumin $(\mathrm{g} / \mathrm{l})$ & 36 & $(15-51)$ & $(21-48)^{\star}$ & 40 & $(18-50)^{\star}$ & 40 & $(25-51)^{\star}$ \\
\hline Anti-dsDNA (IU/ml) & 81 & $(5-99)$ & $(10-99)^{\star}$ & 49 & $(5-99)^{\star}$ & 48 & $(1-16)^{\star}$ \\
\hline C3 $(g / 1)$ & 0.88 & $3(0.16-2.4)$ & $0.9 \quad(0.2-1.8)$ & 0.9 & $(0.22-1.98)^{\star}$ & 0.9 & $(0.32-1.6)^{\star}$ \\
\hline $\mathrm{C} 4(\mathrm{~g} / \mathrm{l})$ & 0.18 & $(0.03-0.47)$ & $0.22(0.06-0.50)^{\star}$ & 0.24 & $4(0.06-0.9)^{\star}$ & 0.23 & $(0.06-0.9)^{\star}$ \\
\hline
\end{tabular}

Table 4 Laboratory changes before and after intravenous cyclophoshamide treatment in systemic vasculitis. Values are median (range)

\begin{tabular}{|c|c|c|c|c|c|c|c|c|}
\hline \multirow{2}{*}{$\frac{\text { Laboratory tests }}{\mathrm{ESR}(\mathrm{mm} 1 \mathrm{st} \mathrm{h})}$} & \multicolumn{2}{|c|}{ Before treatment } & \multicolumn{2}{|c|}{$\begin{array}{l}\text { Initial resonse } 3 \text { ( } 2-10) \\
\text { weeks } 3(2-10) \text { pulses }\end{array}$} & \multicolumn{2}{|c|}{$\begin{array}{l}\text { After the course of treatment } 4 \\
(0.25-37) \text { months } 7(2-50) \text { pulses }\end{array}$} & \multicolumn{2}{|c|}{$\begin{array}{l}\text { At follow up } 39 \\
\text { (6-130) months }\end{array}$} \\
\hline & 44 & $(21-46)$ & 26 & $(2-80)^{\star}$ & 18 & $(2-103)^{\star}$ & 15 & $(1-110)^{\star}$ \\
\hline $\mathrm{CRP}(\mathrm{g} / \mathrm{dl})$ & & $(5-250)$ & & $(5-100)^{\star}$ & & $(5-121)^{\star}$ & 5 & $(5-150)^{\star}$ \\
\hline $\mathrm{Hb}(\mathrm{g} / \mathrm{dl})$ & 12.6 & $(7.4-15.2)$ & 12.7 & $(8.5-16)$ & 13.1 & $(8.2-16)$ & 13.2 & $(7.5-15.7)^{\star}$ \\
\hline Neutrophils $\left(\times 10^{9} / 1\right)$ & 8.55 & $(3-29)$ & 6.85 & $(1.5-26.8)^{\star}$ & 6.4 & $(2.1-26)^{\star}$ & 4.3 & $(2.2-13.5)^{\star}$ \\
\hline Lymphocytes $\left(\times 10^{9} / 1\right)$ & 1.6 & $(0.3-8)$ & 1.2 & $(0.4-5)$ & 1.25 & $(0.1-4.6)$ & 1.6 & $(0.6-3.7)$ \\
\hline Platelets $\left(\times 10^{3} / 1\right)$ & 340 & $(39-1280)$ & 316 & $(124-910)^{\star}$ & 290 & $(16-568)^{\star}$ & 261 & $(152-485)^{\star}$ \\
\hline Creatinine $(\mu \mathrm{mol} / \mathrm{l})$ & 128 & $(87-202)$ & 126 & $(91-174)$ & 128 & $(120-175)$ & 125 & $(95-233)$ \\
\hline Albumin (g/l) & 40 & $(19-48)$ & 40 & $(21-46)$ & 43.5 & $(37-50)^{\star}$ & 43 & $(38-51)$ \\
\hline
\end{tabular}

$\star \mathrm{p}<0.05$ Wilcoxon's signed rank test.

atinine increased from $93(45-250) \mu \mathrm{mol} / 1$ to $112(51-287) \mu \mathrm{mol} / 1$ at the end of follow up but the difference was not significant. These patients were given prednisolone alone $(n=7)$, azathioprine $(n=11)$ or oral cyclophosphamide $(\mathrm{n}=2)$.

Fourteen patients with SLE relapsed while receiving treatment: five were receiving weekly followed by monthly treatment, seven were receiving weekly treatment, and two monthly treatment. These patients were treated with a further weekly course of intravenous cyclophosphamide therapy (eight patients) or further monthly intravenous cyclophosphamide therapy (six patients). Of these patients, four went into partial remission and two into complete remission. The other eight patients were considered to be treatment failures and of these, four patients doubled their serum creatinine concentrations at the end of follow up. Three of these had diffuse proliferative lupus nephritis (WHO grade IV) and one had focal proliferative lupus nephritis (WHO grade III). Two of these patients died and are described later.

Ten patients had active cerebral lupus presenting with organic brain syndromes. All had previously received prednisolone treatment and three received pulse methylprednisolone with no response. Eight patients responded to intravenous cyclophosphamide with complete resolution of the central nervous system signs and symptoms. One patient, a 17 year old man had two further recurrences of auditory hallucinations, which again promptly responded to further intravenous cyclophosphamide. Two did not respond one of whom died and is described below. The other, a 30 year old woman with severe organic brain syndrome who failed to respond to intravenous treatment improved significantly when given oral cyclophosphamide.
Two patients with interstitial pneumonitis did not respond to treatment and high resolution computed tomography showed predominant interstitial fibrosis with no evidence of inflammatory 'ground glass' changes. Five other patients with SLE complicated by severe cutaneous and systemic vasculitis all responded to treatment with complete remission.

\section{SYSTEMIC VASCULITIS}

Complete or partial remission was seen in 31 of 42 patients $(74 \%)$ at the end of follow up. The best responses were seen in patients with Wegener's granulomatosis where 15 of 19 responded $(79 \%)$ and three of three patients with Churg-Strauss syndrome (table 2). However, the median number of pulses received by the Wegener's granulomatosis patients was higher than any of the other patient groups (median 11 pulses, range 4-50 with a median cumulative dose of $5.5 \mathrm{~g}$ ) perhaps reflecting the aggressive relapsing nature of this disease.

There were significant improvements, within a median of three $(2-10)$ weeks, in the acute phase response as measured by the ESR, CRP, neutrophil and platelet counts (table 4). This supports our clinical finding of an early and effective response to intravenous cyclophosphamide. Maintenance treatment resulted in further improvements in these parameters in the group as a whole (table 4).

Although most patients with Wegener's granulomatosis responded initially, there was a significant relapse rate. Of the 19 patients with Wegener's granulomatosis, $11(58 \%)$ relapsed a median of 8.6 months after induction therapy. Seven of these patients who relapsed had received weekly followed by monthly intravenous cyclophosphamide treatment (five patients) or weekly treatment (two patients). The other four patients relapsed while receiving maintenance treatment. Four pa- 
tients received further weekly intravenous cyclophosphamide treatment and three received further monthly treatment and of these there was only one further relapse, which again responded to weekly treatment.

In all, 10 of 11 patients who relapsed responded well to further weekly intravenous cyclophosphamide, the other patient being switched successfully to etopside. The most notable finding in the systemic vasculitis group was that 13 patients, who did not have renal disease, were successfully maintained with azathioprine after intravenous cyclophosphamide treatment.

Four patients with Wegener's granulomatosis did not respond to intravenous cyclophosphamide. One patient was switched to oral cyclophosphamide and three others received monthly oral etoposide with good results one of whom has previously been reported. ${ }^{18}$ One Wegener's granulomatosis patient doubled his serum creatinine by the end of follow up. Two patients died and are described below.

\section{ADVERSE EFFECTS}

A total of seven of 90 patients $(7.8 \%)$ had serious infections during the entire follow up period. These included three episodes of Herpes zoster (one intravenous and two oral cyclophosphamide), three episodes of pneumonia (one intravenous and two oral cyclophosphamide), three episodes of septicaemia (one intravenous and one oral cyclophosphamide, one azathioprine). One patient receiving oral cyclophosphamide had mild alopecia. Three episodes of haemorrhagic cystitis (one intravenous and two oral cyclophosphamide) and five episodes of neutropenia were seen (one intravenous and two oral cyclophosphamide and two azathioprine). Two patients had allergic skin reactions to the mesna. Overall, in the patients receiving intravenous cyclophosphamide, there was no correlation between the number of pulses, the cumulative cyclophosphamide dose, and the incidence of infection. One patient with lupus nephritis did however have two infections after receiving two courses of intravenous cyclophosphamide and a total of 26 pulses. There was a non-significant trend to infection in patients receiving either daily oral cyclophosphamide $(n=11)$ or etoposide $(n=3)$ maintenance treatment $(\mathrm{p}=0.065$, odds ratio 3.7 (0.97-14.5)). No malignancies were noted.

Tables 3 and 4 show that neutrophil, lymphocyte, and platelet counts were marginally reduced during the course of follow up. No correlation was found between the number of pulses, cumulative doses of cyclophosphamide and neutropenia or lymphopenia, or both.

Among the 68 women, 28 were known to have been perimenopausal or postmenopausal at the start of intravenous cyclophosphamide treatment and 40 had regular menstruation. No premenopausal woman who received intravenous cyclophosphamide suffered premature ovarian failure. Table 1 shows that the median cumulative dose received by patients with SLE who were most at risk of ovarian failure was only $2.5 \mathrm{~g}$. Of the 11 patients who received oral cyclophosphamide, five were male and six female: two postmenopausal, four with regular menstruation. All four of the non-menopausal women suffered prolonged amenorrhoea with oral cyclophosphamide.

There were five deaths in all, three with SLE and two with Wegener's granulomatosis. A 30 year old woman with lupus nephritis had severe persistent neutropenia that may have been related to both disease and treatmentshe developed Gram negative septicaemia and died after 10 months of follow up. A 41 year old woman with lupus nephritis died after eight months of follow up from a severe flare of her disease with renal and central nervous system disease that failed to respond to treatment. A 51 year old man with lupus psychosis died from severe SLE that failed to respond to 12 pulses of intravenous cyclophosphamide. Two patients with Wegener's granulomatosis died: one from a pneumonia associated with treatment and one from overwhelming disease that failed to respond.

\section{Discussion}

Cyclophosphamide is a potent immunosuppressive agent acting on T and B lymphocytes. ${ }^{1920}$ While extremely effective, its use is associated with serious adverse effects including bacterial infections, Herpes zoster, haemorrhagic cystitis, neoplasias including bladder malignancies, and premature ovarian failure. ${ }^{52122}$ To minimise these drawbacks, we have introduced the use of cyclophosphamide in an intermittent intravenous low dose pulse regimen.

We studied the long term effect of this regimen in the induction phase of treatment in 90 patients with severe connective tissue diseases having followed them up for a median of 56 months. An excellent response in both clinical and laboratory parameters was seen after the first four weeks of treatment, which was sustained with subsequent maintenance treatment. The clearest long term response to our therapeutic regimen was seen in patients with Churg-Strauss syndrome, neuropsychiatric lupus and in most patients with lupus nephritis. Although there was a high relapse rate in the Wegener's granulomatosis patients, all but one promptly responded to further intravenous cyclophosphamide treatment.

The previously published regimens of intravenous cyclophosphamide, often requiring doses in excess of 1 or $1.5 \mathrm{~g}$ have been associated with significant adverse effects, with infections in up to $10 \%$ and Herpes zoster in as many as $25 \% .^{82}$ Sustained amenorrhoea has been seen in up to $39 \%$ of patients receiving a prolonged monthly treatment with a high dose intravenous cyclophosphamide regimen (a total of 12 pulses or more)..$^{23}$

We have previously published our initial findings using a 'low dose' pulse regimen in connective tissue diseases and reported a significantly lower adverse effect profile without apparently compromising efficacy significantly. ${ }^{1213}$ In this extended study using our St Thomas's Hospital regimen of low dose (500 mg) weekly intravenous pulses we 
confirm that lower doses are effective in inducing remission with far fewer adverse effects and with better tolerance for outpatient clinic use.

Infectious complications were seen in only seven patients $(7.8 \%)$, though two of these patients died of sepsis associated with treatment. Herpes zoster was seen in only one patient $(1 \%)$ receiving intravenous cyclophosphamide compared with $25 \%$ in previous series. $^{82}$ The neutropenia associated with intravenous cyclophosphamide was mild and transient in four of five patients, the fifth patient suffering a fatal infection as described above. Twenty patients were lymphopenic before pulse cyclophosphamide and 18 patients had a further reduction of the lymphocyte count during the treatment course. At the end of the study, this reduction was not statistically significant. We did not observe any significant episodes of thrombocytopenia associated with low dose cyclophosphamide pulses in any patient.

None of our patients suffered ovarian failure associated with intravenous cyclophosphamide. This may be related to the relatively low cumulative dose of intravenous cyclophosphamide - indeed, prolonged menstrual irregularities were only noted in patients receiving long term oral cyclophosphamide. However, premature prolonged amenorrhoea can occasionally occur long after the initial exposure to cyclophosphamide and we continue to monitor our patients for this, particularly given the consequences for osteoporosis.

Mesna was given in 816 of 883 pulses. We had only one patient who suffered from haemorrhagic cystitis during the course of the study. Perhaps significantly, this occurred in one of the patients in whom mesna was omitted. We did not observe any episodes of bladder cancer and these patients continue to be followed up closely. Maculopapular drug eruptions were seen in two patients associated with mesna, a complication previously reported by Zonzits et al. ${ }^{24}$

In terms of efficacy, 22 patients $(24.4 \%)$ were considered to be 'treatment failures' at follow up. Four lupus nephritis patients and one Wegener's granulomatosis patient had more than doubled their serum creatinine concentrations at the end of the study. The risk of doubling serum creatinine was higher among patients with an initial serum creatinine greater than $150 \mu \mathrm{mol} / 1$ (three of five patients). In comparison, Boumpas et al $l^{25}$ noted a $35 \%$ failure rate in patients treated with 'short-course' monthly intravenous cyclophophamide (35\% doubled serum creatinine including $25 \%$ with end stage renal failure). Similarly, Belmont et $a l^{26}$ noted that $30 \%$ of patients failed to maintain stable renal function using monthly intravenous pulses of cyclophosphamide after a mean (SD) of 52 (3) months of follow up. Clearly though direct comparisons between these studies is difficult particularly as our regimen incorporated long term azathioprine as maintenance. Furthermore long term follow up is essential to observe differences that can develop much later. ${ }^{10}$
Although the median prednisolone dose at the end of follow up was $10 \mathrm{mg}$ daily, the range was wide and included patients who still had some disease activity at the time of follow up. The initial corticosteroid dose was relatively low considering the severity of disease and it is possible that oral prednisolone may need to be given for longer periods given the lower doses of cyclophosphamide used in this regimen. This has obvious implications for side effects and osteoporosis prophylaxis in particular is now considered in all these patients.

The main limitations of this study include its retrospective nature with all the problems that entails, including the lack of a standard lupus disease activity measure, which should ideally be used in a prospective way. The patients are very heterogenous, reflecting clinical practice and different maintenance treatments have been used, perhaps highlighting our uncertainty about the ideal treatment for keeping these diseases under control once remission has been achieved. Nevertheless, our results are encouraging enough to embark upon a randomised prospective study of the low dose intravenous cyclophosphamide regimen in comparison with the standard high dose monthly intravenous cyclophosphamide regimen in the treatment of proliferative lupus nephritis that is currently under way in Europe.

In summary, our clinical experience with this large cohort of patients suggests that the low dose intravenous cyclophosphamide regimen was as therapeutically effective as other previously published regimens with far fewer adverse effects and good tolerance, important in outpatient clinic practice. The most important advantage of this regimen seems to be the relative lack of ovarian toxicity.

This study was supported by Lupus UK and the Special Trustees for St Thomas's Hospital.

1 Walton EW. Giant cell granuloma of the respiratory tract (Wegener's granulomatosis). BMJ 1958;ii:265-70.

2 Fauci AS, Haynes BF, Katz P, Wolff SM. Wegener's granulomatosis. Prospective clinical and therapeutic experience with 85 patients for 21 years. Ann Intern Med 1983; 98:76-85.

3 Fauci AS, Wolff SM. Wegener's granulomatosis: Studies in eighteen patients and a review of the literature. Medicine 1973;52:535-61.

4 Hollander D, Manning RT. The use of alkylating agents in the treatment of Wegener's granulomatosis. Ann Intern Med 1967;67:393-98.

5 Fauci AS, Katz P, Haynes BF, Wolff SM. Cyclophosphamide therapy of severe systemic necrotizing vasculitis. $\mathrm{N}$ Engl J Med 1979;301:235-38

6 Bombardieri S, Hughes GRV, Neri R, Del Bravo P, Del Bono L. Cyclophosphamide in severe polymyositis. Lancet 1989;i:1138-9.

7 Balow JE, Austin HA, Tsokos CT, Antonovych TT, Steinberg AD, Klippel JH. NIH Conference: Lupus nephritis. Ann Intern Med 1987;106:79-94.

8 Austin HA III, Klippel JH, Balow JE, Le Riche NGH, Steinberg AD, Plotz PH, et al. Therapy of lupus nephritis: Steinberg AD, Plotz $\mathrm{PH}$, et al. Therapy of lupus nephritis:
Controlled trial of prednisone and cytotoxic drugs. N Engl J Med 1986;314:614-19.

9 Balow JE, Austin HA, Muenz LR, Joyce KM, Antonovych TT, Klippel JH, et al. Effect of treatment on the evolution of renal abnormalities in lupus nephritis. $N$ Engl J Med 1984;311:491-5.

10 Steinberg AD, Steinberg SC. Long-term preservation of renal function in patients with lupus nephritis receiving treatment that includes cyclophosphamide versus those 34:945-50.

11 Scott DG, Bacon PA. Intravenous cyclophosphamide plus methylprednisolone in the treatment of systemic rheumatoid vasculitis. Am J Med 1984;76:377-84. 
12 Haga HJ, D'Cruz D, Asherson RA, Hughes GRV. The short-term effect of pulse cyclophosphamide in the treatment of conn

13 Houssiau FA, D’Cruz DP, Haga HJ, Hughes GRV. Weekly low dose pulse cyclophosphamide in the treatment of lupus nephritis: A preliminary study. Lupus 1991;1:31-5.

14 Tan EM, Cohen AS, Fries JF, Masi AT, McShane DJ, Rothfield NF, et al. The 1982 revised criteria for the classification of systemic lupus erythematosus. Arthritis Rheum 1982;25:1271-7. 15 Hunder GG, Arend WP, Bloch DA, Calabrese LH, Fauci
AS, Fries JF, et al. The American College of Rheumatology 1990 criteria for the classification of vasculitis. Arthritis Rheum 1990;33:1065-144.

16 Tzioufas AG, Manoussakis MN, Drosos AA, Silis G, Gharavi AE, Moutsopoulos HM. Enzyme immunoassays for the detection of IgG and IgM anti-ds DNA antibodies. the dinical significance and specificity. Clin Exp Rheumatol 1987;5:247-53.

17 Bryant BM, Jarman M, Ford HT, Smith IE. Prevention of isophosphamide-induced urothelial toxicity with 2-mercaptoethane sulfonate sodium (Mesnum) in patients

18 D'Cruz D, Payne H, Timothy A, Hughes GRV. Response of cyclophosphamide resistant Wegener's granulomatosis to etoposide. Lancet 1992;340:425-6.

19 Cupps TR, Edgar LC, Fauci AS. Suppression of human B lymphocyte function by cyclophosphamide. J Immunol 1982;128:2453-7.
20 Clements PJ, Davis J. Cytotoxic drugs: their clinical application to the rheumatic diseases. Semin Arthritis Rheum 1986;15:231-54.

21 Stillwell TJ, Benson RCJ, De Remee RA, McDonald TJ. Cyclophosphamide induced bladder toxicity in Wegener's granulomatosis. Arthritis Rheum 1988;31:465-70.

22 Hoffman GS, Kerr GS, Leavitt RY, Hallahan CW, Lebovics RS, Travis WD, et al. Wegener's granulomatosis: analysis of 158 patients. Ann Intern Med 1992;116:488-92.

23 Boumpas DT, Austin HA, Vaughn EM, Yarboro CH, Klippel JH, Balow JE. Risk for sustained amenorrhoea in patients with systemic lupus erythematosus receiving intermittent pulse cyclophosphamide therapy. Ann Intern Med 1993;1 19:366-9.

24 Zonzits E, Aberer W, Tappeiner G. Drug eruptions from mesna after cyclophosphamide treatment of patients with systemic lupus erythematosus and dermatomyositis. Arch systemic lupus erythemato

25 Boumpas DT, Austin HA, Vaughn EM, Klippel JH, Steinberg AD, Yarboro $\mathrm{CH}$, et al. Controlled trial of pulse methylprednisolone versus two regimens of pulse cyclophosphamide in severe lupus nephritis. Lancet 1992; 340:741-5.

26 Belmont HM, Storch M, Buyon J, Abramson S. New York University/ Hospital for joint diseases experience with intravenous cyclophosphamide treatment: efficacy in steroid unresponsive lupus nephritis. Lupus 1995;4:104-8. 